

\title{
Semiótica discursiva na análise de um cartaz do vestibular da UEG: a questão do sentido
}

\author{
Discussion semiotics in the analysis of a poster of the UEG \\ vestibular: the question of sense
}

\author{
Jorge Lucas Marcelo dos Santos* \\ Maria Eugênia Curado
}

\begin{abstract}
Resumo: O presente artigo visa a discutir, por meio da análise de um cartaz para divulgação do vestibular da Universidade Estadual de Goiás, veiculado em 2016, questões de caráter paradoxal que perpassam o Plano de Conteúdo (PC) articulado ao Plano de Expressão(PE) e que se revestem de sentido. Para tal investigação, lançaremos mão dos pressupostos da semiótica discursiva com apoio em Greimas.
\end{abstract}

Palavras-chave: Plano de expressão (PE). Plano de conteúdo (PC). Cartaz vestibular 2016/1-UEG.

Abstract: The main goal of this paper is to discuss by analysis the vestibular poster that was used to promote the vestibular of State University of Goiás in 2016/1. So, we are going to verificate some paradoxical questions which are in the content plan (PC) articulated to the expression plan (PE). For such an investigation, we shall focus the assumptions of discursive semiotics with support by Greimas.

Keywords: Expression plan. Content plan. Vestibular poster 1/2016-UEG.

\footnotetext{
* Mestrando do Programa Interdisciplinar em Educação Linguagem e Tecnologias da Universidade Estadual de Goiás -PPG-IELT/UEG. E-mail: jorgelucasletras@, hotmail.com

** Doutora em Comunicação e Semiótica pela Pontifícia Universidade Católica de São Paulo - PUC-SP. Docente do Programa de Pós-Graduação Interdisciplinar em Educação, Linguagem e Tecnologias da Universidade Estadual de Goiás PPG-IELT/UEG
} 
Para uma análise dos fenômenos semióticos em geral, tem-se que discorrer primeiramente sobre dois termos teóricoconceituais, que, segundo Greimas (1966) e Greimas e Courtés (1979), em Semântica estrutural e em Sémiotique: dictionnarie raisonné da la théoria du language, e Fontanille (2018), em Semiótica do discurso, são: sentido e significação.

Em primeiro lugar, o sentido é uma direção, e é, ao mesmo tempo, uma "tendência a algo", que comumente se revela por meio de um objeto, uma prática ou uma situação de interação semiótica, conforme assinala Fontanille (2018), pautado em Greimas (1966), em Semiótica do discurso. Nesse sentido, a teoria semiótica, em especial a greimasiana, busca examinar as estruturas subjacentes à materialidade significante, quer seja um texto escrito ou não, buscando evidenciar seu processo de significação a fim de denotar sutilezas da geração do sentido sob um percurso, tomando o sentido por sua inteligibilidade. Ao que se refere à significação, a concluir, juntamente com Fontanille (2018), ancorado em Greimas (1966), que "é o produto organizado pela análise", e que se revela "na e pela" associação e articulação do plano de conteúdo de um discurso com o seu plano de expressão, projetando para o mundo significante uma unidade textual e discursiva inteirada por semioses analisáveis.

Greimas e Courtés (2011) diz ainda que o processo de significação de um texto deve ser observado na totalidade de sua manifestação, tendo sua análise textualmente orientada, ou melhor, analisa-se seu processo de significação sobrepondo o encadeamento de signos junto às interações discursivas que se materializam entre as grandezas do plano de expressão (do significado) e do plano de 
conteúdo (do significante) do texto analisado.

Sublinhamos, por conseguinte, que, para Greimas (1966), os signos (o significante e o significado) não pertencem a uma realidade pronta e acabada, mas sim a um "conjunto de sistemas semióticos" que se fazem presentes entre as tensões do mundo "verbal" e do mundo "natural", numa constante relação retroalimentar, acomodando sempre as imperfeições que cercam a vida e as experiências humanas no momento do ato de linguagem.

Consoante a isso, Greimas (2017), em Da imperfeição, extrapola a compreensão primeira dada à semiótica greimasiana fundamentalmente inspirada nos trabalhos com a linguística estrutural de Saussure (2006), redirecionando o seu fazer semiótico - ou toda a teoria semiótica greimasiana - à análise semiótica arquitetada sob o princípio da imperfeição ${ }^{1}$, buscando, a partir disso, analisar o sentido não somente nas estruturas inerentes à geração do sentido, mas o colocando dentro das práticas sociais, no âmbito das vivências humanas, ou, em outras palavras, no nível do vivido, no nível da presença, pois "a única coisa que, sob uma forma ou outra, poderia realmente nos estar presente, é o sentido", conforme diz a sociossemiótica de Landowski (2012).

O signo na perspectiva da semiótica discursiva, portanto, não pode ser compreendido por uma "gramática do discurso", pois seus significantes e significados são solidários às interferências de

1 Da imperfeição, de Greimas (2017), propõe uma releitura das estruturas inerentes à geração do sentido, pois, para ele, o sentido (e o texto) é interseccionado por conotações sociais, culturais e contextuais. Então, cabe à semântica enquanto linguagem extrapolar suas fronteiras sendo inteirada por semioses que lhe impõe sentido, por meio da análise do discurso. Tem-se assim em Greimas uma "poética semiótica" que se ocupa das noções de texto, sentido e de significação face à sensibilidade das experiências humanas. 
ordem social e cultural, semelhante ao que ocorre com o discurso. Neste último, o discurso, é reconhecido pelo processo semiótico que o constitui, ou melhor, a noção de discurso pertence à ordem das interações discursivas, seja por fontes semióticas linguísticas (línguas naturais) ou não linguísticas (figuras). As estruturas da significação, portanto, se preenchem de sentido no encadeamento dos signos semióticos, no encontro de seus significados e significantes, no interior do ato de linguagem (a linguagem enquanto comunicação). A linguagem, considerada como suporte para o discurso, reúne as condições para a manifestação dos sentidos, no nível discursivo, por exemplo, do percurso gerativo de sentido, Greimas e Courtés (2011) diz que ocorrerá a discursivização das unidades encontradas nos níveis fundamental e narrativo da geração do sentido. Nesses termos, a linguagem é tomada por sua complexidade epistemológica, ora se relacionando à comunicação e ao simples intercâmbio de informações, ora se relacionando e determinando a noção de discurso por meio de atos de linguagem, ou melhor, por meio de textos. Diante a isso, estendemos a problemática do conceito "linguagem" à linguística, que, segundo Benveniste (1976), em Problemas de Linguística Geral, é dada à linguagem a compreensão de realização do sistema da língua em que seus signos (significados e significantes) passem a constituir o discurso. A partir disso, então, Greimas precisou a noção de discurso para a semiótica, colocando da seguinte forma:

"[...] pode-se identificar o conceito de discurso como o de processo semiótico e considerar como pertencente à teoria do discurso a totalidade dos fatos semióticos (relações, unidades, operações, etc.) situados no eixo sintagmático da linguagem”. 
(GREIMAS; COURTÉS, 2011, p. 114)

Em outras palavras, para Fontanille (2018), respaldado em Greimas, o discurso é uma unidade de sentido que se reveste de função semiótica, sendo esta imediatamente atingida pelas profundas correlações inscritas nos planos de conteúdo e de expressão de um texto, reafirmando a noção de discurso para a semiótica greimasiana.

A sociossemiótica, que tem suas bases epistemológicas em Greimas, propõe transgredir a noção de discurso como "unidade de sentido", o que para Landowski, o discurso assemelha-se a noção de signo semiótico, pois é constantemente atualizado pela linguagem e por várias outras semioses, excluindo, portanto, a noção de discurso enquanto um simples ato de fala, pois:

[...] de resto, se o "discurso" (verbal, claro, mas também o do olhar, do gesto, da distância mantida) nos interessa, é porque ele preenche não só uma função de signo numa perspectiva comunicacional, mas porque tem ao mesmo tempo, valor de ato: ato de geração de sentido. (LANDOWSKI, 2012, p. 5)

Ainda, segundo Landowski (2012), é tarefa impossível pretender dizer o sentido, pois este se revela "numa série de contextos intersubjetivos, e, portanto, interativos, precisos" sendo construído e atualizado no ato de geração de sentido pela linguagem. O texto, o discurso e o sentido são, portanto, elementos conceptuais e operatórios para semiótica discursiva, ou talvez, são responsáveis por uma semiótica da presença, esta concebida sob a proposição do ato de presentificação. Sendo assim, as condições históricas, 
sociais e culturais que ocorrem no discurso alteram seus efeitos de sentido, confirmando a tese de que "o sentido ora se faz, ora se dissolve" no contexto de sua presença. É pela semiótica do discurso que se chega à geração do sentido, a seus efeitos e a sua direção. A partir disso, parafraseando Landowski (2012), questionamos inicialmente: "a que figuras, a que dispositivos, a que linguagens" se recorreram para que um pouco de sentido se revelasse como presença no cartaz sob análise?

Exposto isso, considerando as noções de texto e de discurso aqui contempladas, tomamos o cartaz para divulgação do vestibular de 2016/1, da Universidade Estadual de Goiás (UEG), como corpus de nosso trabalho. Assim, objetivamos analisar semioticamente o discurso que intersecciona os planos de conteúdo e de expressão do cartaz já mencionado. Para atingirmos o objetivo central deste trabalho, utilizaremos como recurso teórico-metodológico a análise do percurso gerativo de sentido proposta por Greimas (1975), para quem "o fazer semiótico é uma práxis científica”, ou seja, a partir de um objeto observável pode-se construir um objeto teórico, ou melhor, "um ir-e-vir entre o construído e o observável".

Fiorin (2001), apoiado em Greimas (1966, p. 18), diz que o percurso gerativo de sentido "é uma sucessão de patamares, cada um dos quais suscetível de receber uma descrição adequada, que mostra como se produz e se interpreta o sentido." Nessa mesma empreitada, Barros (2011) conclui que o percurso gerativo de sentido de um texto é constituído por suas estruturas fundamentais, estruturas narrativas e, por fim, por suas estruturas discursivas.

Para tanto, antes da análise, regatamos algumas marcas do contexto de produção e de recepção do texto-objeto escolhido para 
análise, que é o cartaz do vestibular de 2016/1, da Universidade Estadual de Goiás - UEG. Em resumo, pode-se dizer que é senso comum que no ainda no atual contexto cultural, a imagem e as representações sociais da pessoa negra são constantemente tomadas como referência de subcultura, submissão e opressão. Do ponto de vista das relações étnico-raciais, a representatividade negra tem sido estigmatizada, estereotipada e subordinada aos discursos hegemônicos, sob forte influência eurocêntrica. O protagonismo negro foi historicamente inferiorizado face às expressões socioculturais dos grupos dominantes, ou melhor, do grupo dominante (o do homem branco, heterossexual e cristão). No campo da ideologia, por meio de discursos ideológicos (culturais, históricos e sociais), deparamo-nos com "naturalização" da real condição da pessoa negra no Brasil, bem como se percebe na construção da identidade negra forjada a serviço dos grupos dominantes e com forte intuito discriminatório, apontando sempre o lugar social do negro de onde lhe impõem características subjugadas. Vejamos o cartaz: 
Figura 1 - Cartaz do vestibular UEG-2016/1

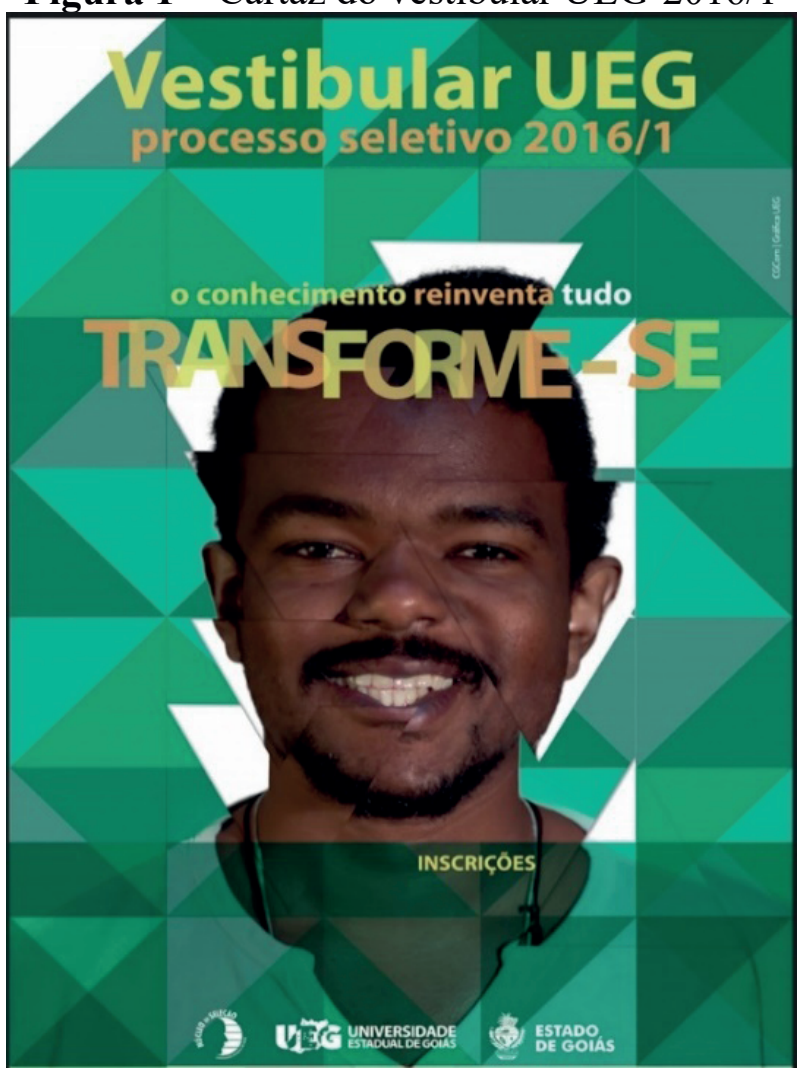

Fonte: Universidade Estadual de Goiás (2016).

Tendo em vista tais considerações, é perturbador intimar o "vestibulando" a se "reinventar" e a se "transformar", como se vê no cartaz do vestibular de 2016/1 da UEG. Perdeu-se com isso uma significativa reação ao racismo na universidade, ou até mesmo ao racismo institucionalizado, mostrando por consequência uma quebra do paradigma estabelecido fortemente pela sociedade de que o lugar do negro não seja na universidade, mas sim fora dela. Pontuado isso, sublinhamos que a universidade pública é o lugar 
da diferença, da multiculturalidade e da interculturalidade. Por fim, ressaltamos ainda, segundo Boaventura de Sousa Santos (2003, p. 56), que "temos o direito a ser iguais quando a nossa diferença nos inferioriza; e temos o direito a ser diferentes quando a nossa igualdade nos descaracteriza".

No âmbito acadêmico, lugar profícuo a discussões político-ideológicas, o zelo pela identidade negra positiva poderia potencializar o protagonismo negro, reiterar as ações afirmativas da universidade, bem como manter a heterogeneidade do corpo discente da instituição. É bom salientar que ao se propor discutir "racismo", pode-se provocar "racismo", quando os recursos linguísticos e semióticos são indevidamente manipulados, ou devidamente manipulados para essa finalidade. Assim, deparamonos novamente com a presença, mas não só com a presença empírica da alteridade, mas sim com a presença do discurso, da "ideologia" e da "enunciação" como práticas de linguagem sob interferências sociais, históricas e culturais ainda que subliminares.

No que se refere à noção de "enunciação", Fiorin diz tratarse de uma "entidade semiótica" na condição de uma "atividade discursiva", o que para Landowski (2012) tem valor de "ato de linguagem" ou de "ato de sentido". O enunciado, portanto, seria o produto da enunciação - esta somente é acessada por meio de suas marcas deixadas no enunciado - podendo, assim, por meio da análise semiótica discursiva, reconstruir o ato enunciativo, conforme diz o estudioso. Nesse sentido, o sujeito enunciador se reveste, segundo Fiorin (2016) por certas competências linguísticodiscursivas que dizem respeito à gramática e ao léxico: 
a) competência discursiva, que diz respeito a discursivização por meio de figuras e temas;

b) competência textual, que diz respeito ao saber utilizar a semiótica-objeto;

c) competência interdiscursiva, que diz respeito à heterogeneidade do discurso;

d) competência intertextual, que se refere às relações contratuais ou polêmicas de um texto com os outros textos;

e) competência pragmática, que concerne aos valores ilocutórios dos enunciados;

f) competência situacional, que diz respeito a situação de que se dá a comunicação.

Essas competências podem ser mais ou menos comuns ao enunciador e ao enunciatário, conforme Fiorin. Por esse caminho, os sujeitos envolvidos na ação comunicativa, ou melhor, na "atividade discursiva", se valem de suas competências linguístico-discursivas para entrever a geração do sentido. Este, o sentido enquanto semiose, manifesta-se sob a forma de "texto", o que lhe confere uma condição de unidade analisável. Além disso, esses sujeitos são constituídos por seus valores, os quais, consequentemente, se tornam parte do ato de enunciar.

Portanto, se uma das questões deste artigo é a de matizar a noção de sentido, vale dizer ainda que é por meio da descrição do ato enunciativo que se chega à geração do sentido e de sua significação. Para a semiótica discursiva, as seis competências discutidas por Fiorin corroboram com o alcance da significação das 
estruturas e níveis semióticos. Greimas coloca que para uma análise do percurso gerativo de sentido as noções de "plano", "estrutura" e de "nível" devem ser compreendidas face aos recursos conceptuais e operatórios que dispõe a semiótica discursiva.

As reflexões feitas até aqui derivam de uma concepção de língua para além daquela proposta por Saussure, de que a língua seja um "sistema de signos", mas, para a semiótica, a língua é um "sistema de signos e figuras"- e de temas -, conforme postulado por Hjelmslev (1973). Portanto, importa-nos dizer ainda que a chave de entrada para a análise do cartaz em questão é o paradoxo construído entre a linguagem verbal que, desde a primeira leitura, figurativiza "um homem transformável" e uma linguagem visual que, de forma explicita, mostra o rosto de um homem negro, o que, automaticamente, aciona tudo o que este rosto representa ideológica, histórica, social e culturalmente. Para Greimas e Courtés (2011), “os procedimentos de figurativização de um discurso colocado a princípio como neutro e abstrato" são revelados dentro do percurso gerativo de sentido, que pela narratividade do discurso, evidencia a posição do narrador-enunciador na criação de estratégias e atividades em face do convite ao vestibular, tendo o sentido manifestado por meio de dois planos: o de expressão (PE) e o de conteúdo (PC). Nesse momento, pode-se afirmar que o PC acomoda as interações discursivas que são concretizadas por uma expressão, ou melhor, pelo PE.

Segundo Barros (2011), cabe a semiótica greimasiana "explicar o ou os sentidos do texto pelo exame, em primeiro lugar, de seu plano do conteúdo", pois como orienta Floch (2001) uma análise semiótica de texto sincrético se inicia pelo plano de 
conteúdo, tendo em vista a busca dos conceitos temas presentes no texto e no discurso. Por se tratar aqui de um texto sincrético, segundo Teixeira (2004, p. 14), respaldada em Greimas:

Objetos sincréticos, para dizer com mais rigor, são aqueles em que o plano de expressão se caracteriza por uma pluralidade de substâncias mobilizadas por uma única enunciação cuja competência de textualizar supõe o domínio de várias linguagens para a formalização de uma outra que as organize num todo de significação.

Nessa perspectiva, entende-se que o texto sincrético é o produto de um processo enunciativo capaz de gerar sentido, em outras palavras, entende-se que o texto sincrético é compreendido por um único ato de enunciação, que é analisável do ponto de vista semiótico, pois seu conteúdo e sua expressão se completam e geram o sentido no interior do texto e do discurso. Destarte, a semiótica discursiva, com bases na Semântica estrutural de Greimas, herdou seu comprometimento com o rigor e o método de análise linguística textualmente orientada, mas, sobretudo, tem se voltado à análise de diferentes materialidades significantes, o que possibilita a análise de objetos sincréticos sob os pressupostos teórico-metodológicos da semiótica greimasiana, como ênfase na averiguação do percurso gerativo de sentido.

$\mathrm{O}$ conceito de nível fundamental, em que surgem as estruturas fundamentais, é a primeira etapa do percurso gerativo de sentido, sendo a mais simples e abstrata, a significação surge aqui como oposição semântica mínima. Assim sendo, neste cartaz, observam-se posições político-sociais como estruturas axiológicas 
elementares, opressão vs. liberdade, em outras palavras, classe opressora/não-transformável vs. classe oprimida/transformável. Estas relações são substancialmente permeadas por valores modais como, por exemplo, o poder e o saber.

Ainda, como aponta Barros (2011), consoante aos postulados de Greimas, as posições semânticas manifestam-se de forma explicita no texto, neste caso, nota-se isso pelo uso dos verbos "inventar/reinventar" e "formar/transformar" que tematizam o percurso da "opressão" até a liberdade do "oprimido", bem como a escolha da imagem. Essas oposições de base se preenchem de valor, positivo e negativo, e geram a organização fundamental do texto. No texto em análise, a "liberdade" é eufórica, a "opressão", disfórica. Vale lembrar que a positividade e a negatividade são dadas pelo discurso e não pelo enunciatário. Tem-se, sob hipótese, que a opressão (negativa) passará à liberdade (positiva) somente pela força dos sujeitos. Assim temos:

Plano de conteúdo:

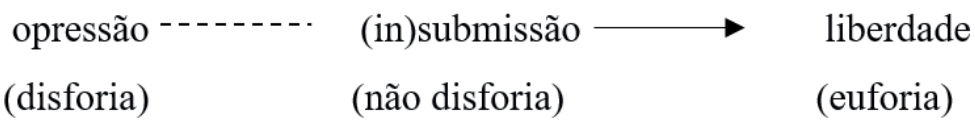

Plano de expressão:

opressão------.. submissão

imagem de um homem negro

$$
\begin{gathered}
\text { imagem ao centro, } \\
\text { junto ao sorriso }
\end{gathered} \begin{gathered}
\text { cores verde, amarela } \\
\text { e branca }
\end{gathered}
$$

Para Barros (2011) "as relações semissimbólicas são, no fundo, relações entre conteúdo e expressão" e que se revelam no 
intercruzamento de linguagens solidárias. Sendo assim, com as oposições semânticas examinadas junto ao plano de expressão, surgem os determinantes para a geração semissimbólica do sentido, filiados à imagem, às cores e às emoções, ou melhor, aos elementos extralinguísticos.

Segundo Castilho (2014), os verbos do ponto de vista semântico "expressam estados de coisas", é o que se tem então de subjetividade linguística perceptível; já do ponto de vista discursivo, considera-se como verbo a palavra "que introduz participantes no texto, via processo de apresentação", dessa maneira, os sintagmas verbais "reinventar" e "transforma-se" estão preenchidos por certa carga semântica e discursiva, como já apontado por Castilho.

Destaca-se, como registra a literatura gramatical, que os verbos empregados no modo imperativo dentro da estrutura linguística são automaticamente associados à postura de ordem por parte de seu enunciador. Nesse sentido, mensurar a força da função conativa (ou apelativa) da linguagem no interior das estruturas analisadas é imprescindível para nossa análise. Segundo Fiorin (2011), para Jakobson, os textos que apresentam a função conativa da linguagem produzem um efeito de sentido de interação com o destinatário dominante, a fim de convencê-lo ou de persuadi-lo. Por fim, consultamos o dicionário de verbos da Língua Portuguesa de Borba (1997) para melhor compreendermos as escolhas lexicais feitas para o cartaz analisado. Segundo o dicionário os verbos "reinventar" e "transformar-se" significam respectivamente: 1. tornar a inventar, recriar uma solução para um problema antigo, mas que exige uma nova abordagem; reelaborar; 2 . dar nova forma a; passar a possuir uma nova forma. Com isso, salientamos que 
esses verbos, ou melhor, essas escolhas lexicais já apontam para um discurso estereotipado e "naturalizador" da condição do negro face ao vestibular: deve "transformar-se".

Segundo Barros (2011), baseada em Greimas (1966), o nível narrativo, que é a segunda etapa do percurso, é onde se encontra a unidade formal da narrativa, que é o programa narrativo. Este nível refere-se a(as) narrativa(as) pressuposta(as) pelo encadeamento dos elementos semióticos e por suas semioses dentro do plano de conteúdo. Para além disso, o percurso narrativo está sob a ordem da experiência, da situação e da sensibilidade dos sujeitos que incidem com os sentidos e os põem significando no entrelaçar das interações discursivas e semionarrativas. No cartaz analisado, o sujeito enunciador opera, nas suas estruturas narrativas, a transformação que põe o sujeito enunciatário em situação de opressão. Com isso, pode-se afirmar que a liberdade é valor desejável pelo enunciatário do cartaz, sendo modalizada pelo querer dentro do percurso da manipulação, mas negada pela força opressora que atua sobre suas relações mediante o poder e o saber do enunciador. Assim proposto por Greimas (2011):

Figura 2 - Manipulação - ação do ser humano sobre outro ser humano

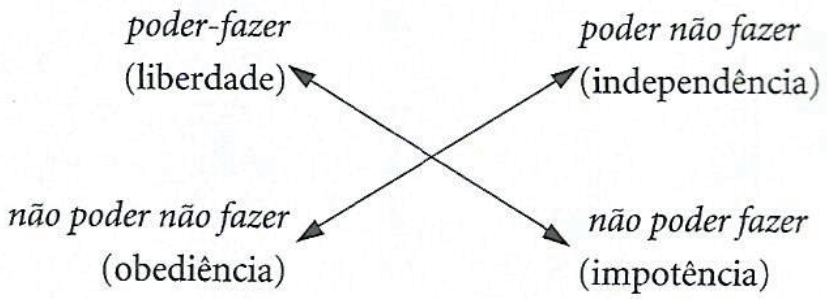

Fonte: Greimas e Courtés (2011). 
A ação do ser humano sobre as coisas pode ser denominada de "operação", ao contrário disso, como se vê no esquema acima, a ação do ser humano sobre outro ser humano é denominada de “manipulação”. Para Greimas e Courtés (2011) a manipulação tem como característica levar o sujeito manipulador a fazer com que o sujeito manipulado execute um (ou mais) programa narrativo dado. Para essa finalidade, o sujeito manipulador pode usufruir do valor modal de poder para configurar o programa narrativo da manipulação. No cartaz analisado, o desejo de liberdade do enunciatário, ou melhor, do manipulado, é reprogramado pela forte imperatividade (lexical) utilizada sob a ordem do poder-saber. Na mesma direção, a manipulação do saber leva o manipulado a confrontar-se com as imagens de sua própria competência, que, no caso do cartaz analisado, é totalmente negativa.

A partir da projeção inicial do percurso da manipulação no quadrado semiótico proposto por Greimas e Courtés (2011), reorganizamos seus itens lexicais para torná-los mais próximos de nossa análise. Assim, para o texto em questão, não se trata exatamente de oposições entre "liberdade x impotência" ou "obediência x impotência”, mas sim de opressão e negação da liberdade real e/ ou simbólica do sujeito enunciatário, ou melhor, configura-se aqui uma oposição semântica assim constituída: opressor x oprimido. Conclui-se aqui pela análise no nível fundamental do percurso gerativo de sentido, bem como pelo ordenamento dos elementos semióticos propostos pelo sujeito enunciador como, por exemplo, as escolhas lexicais (verbos no imperativo) e pela escolha da imagem de um homem negro, centralizada e disforante, que há ocorrência de um paradoxo que perpassa o PC e seu PE no cartaz analisado. 
Esse paradoxo existente no cartaz é responsável por revelar o posicionamento do sujeito enunciador que é bem dissonante da real condição dos negros na contemporaneidade. Assim, propomos a seguindo leitura no plano de conteúdo do cartaz analisado:

Plano de conteúdo:
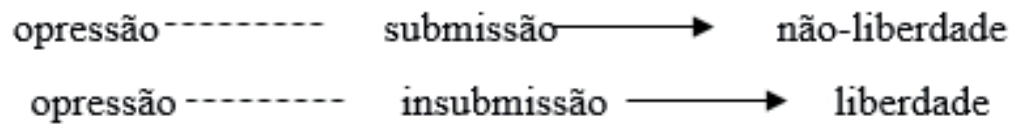
insubmissão liberdade

Segundo Barros (2011), fundamentada em Greimas (1966), "no nível das estruturas narrativas, as operações da etapa fundamental devem ser examinadas como transformações operadas por sujeitos", o que implica dizer, sobre o cartaz analisado, que o sujeito opressor tenta manipular o sujeito oprimido que está revestido por valores subjugados e desmedidos pelo sujeito opressor no interior do cartaz analisado.

No nível discursivo, último patamar do percurso gerativo de sentido, corresponde à tematização e figuratização das oposições semânticas já examinadas no nível fundamental e narrativizadas no nível das estruturas narrativas. A discursivização acontece sob o propósito de se chegar à(às) narrativa(as) que antecede(m) o próprio ato de enunciar, e para então determinar os aspectos ideológicos imanentes desse processo, sendo a narrativa, portanto, direcionada por sua estrutura fundamental e sendo por ela regida. As figuras, ou a figurativização, para Greimas (2017), é como uma "tela" cujas imagens se manifestam e vão além de seus sentidos ordinários, e que, por meio delas, o texto se edifica. Das figuras do nível discursivo emergem as temáticas discutidas pelo enunciador, que, 
pela análise aqui realizada, são questões relativas às práticas sociais de linguagem pautadas no embate entre o "opressor" e o "oprimido", pois, segundo Barros (2011), "tematizar um discurso é formular os valores de modo abstrato e organizá-lo em percursos", bem como proceder a figuratização seja um "procedimento [em que] as figuras do conteúdo recobrem os percursos temáticos abstratos atribuindo traços de revestimento sensorial". Agora resta-nos responder se o sincretismo presente no texto analisado é resultado de um processo significando notável no nível discursivo.

A partir do sincretismo do texto verbal com a imagem do "oprimido", ou melhor, "de um homem negro transformável”, com forte figuratização cromática e com a ausência de representações positivas de que ocorrem nos percursos de empoderamento e de liberdade, essa imagem, ou essa figura, é reforçada pela colocação icônica de um homem negro sob a ordem de "transformar-se", pois é sabido que há valor nesse processo de figuratização e "que a partir de um único valor podem-se obter diferentes percursos temáticos em um mesmo discurso".

As estruturas discursivas podem revelar uma certa objetividade do discurso, por usar elementos gramaticais em terceira pessoa, por exemplo, mas, na verdade, trata-se de uma "ilusão de objetividade". Sob sua competência discursiva, no cartaz aqui analisado, o sujeito do saber manipula o querer do enunciatário dizendo: $O$ conhecimento reinventa tudo. Transforme-se. Com a figurativização do sujeito "oprimido", vários temas passam a realizar os valores que emergem dessa figuratização, que, em primeira análise, estão relacionados aos pólos negativo e positivo da oposição semântica primária, ou seja, o tema do racismo que se 
revela pela colocação da figura de um "homem negro" ao centro do cartaz com a seguinte legenda: O conhecimento reinventa tudo. Transforme-se; sendo este um exemplo indireto de imposição de poder e de identidade elitizada sob o viés eurocêntrico de concepção de homem branco (e graduado):

(a). o racismo é um fenômeno social tão antigo quanto a humanidade, destina-se ao juízo de "valor", provocando processos discriminatórios face a presença simbólica e empírica do outro. A(as) violência(as) social, intelectual, cultural, é sempre perversa e deve ser combatida dentro e fora dos campos universitários. Em oposição a isso, tomado por sua competência discursiva, o sujeito oprimido se movimenta e se reveste de resistência, militância e empoderamento, distanciando-se da opressão devastadora que impera sobre a superfície discursiva ora analisada;

(b). tema da violência, real e/ou simbólica, que implica no surgimento de outras temáticas como, por exemplo, a do preconceito, do racismo e da escravidão, promovendo assim uma verdadeira "política racial", ou seja, uma política pautada na objeção de inferiorização do homem negro, desvalorizando seu trabalho, seu conhecimento, suas práticas e sua cultura. Sob o princípio da resiliência, a identidade negra tem se mostrado forte, impetuosa e, como linguagem, tem sido apreciada;

(c). tema da opressão sociocultural como discurso deslegitimador da identidade negra, subjugando, de novo, o lugar, as potencialidades e o protagonismo da pessoa negra face suas práticas sociais e sua linguagem. A opressão que se recai sobre as expressões culturais subjugadas é uma perversa incompreensão do que se sabe sobre inclusão cultural e exclusão social. Na contramão disso, 
tem-se a noção de liberdade historicizada e discursivizada como escopo às manifestações socioculturais dos grupos marginalizados, levando-os à resiliência, resistência e força.

Tais temas se entrelaçam e correspondem à herança histórica, real e simbólica, da qual os negros estão imersos, como se percebe no cartaz analisado. Em contrapartida, há como oposição sumária o percurso figurado pelo tema da liberdade. Este é tematizado a partir do pólo positivo, desmascarando os valores do enunciador deixados nos enunciados no momento de sua enunciação. Ressaltamos aqui que esses temas são imbricados, se intersecionam e se revelam dentro dos percursos do "opressor" até o seu alvo, o "oprimido", negando sua liberdade, confrontando os discursos legitimadores da diversidade, da heterogeneidade social, ideológica, cultural, racial e muitos outros.

Portanto, o texto analisado é discursivamente disforizante, pois seu percurso temático e figurativo está orientado para a opressão disfórica, mas, talvez, dado seu contexto de circulação, esperava-se um texto euforizante, porque o percurso desse tipo de texto é orientado pela/para a liberdade eufórica. Por fim, a figura que segue logo abaixo é a representação das estruturas elementares do texto analisado, ou em outras palavras, é a representação das relações semânticas primárias sob as tensões da "opressão $\mathrm{x}$ liberdade", cujas nuances são representadas e operacionalizadas no quadro semiótico, como aponta Barros (2011): 
Figura 3 - Quadrado semiótico

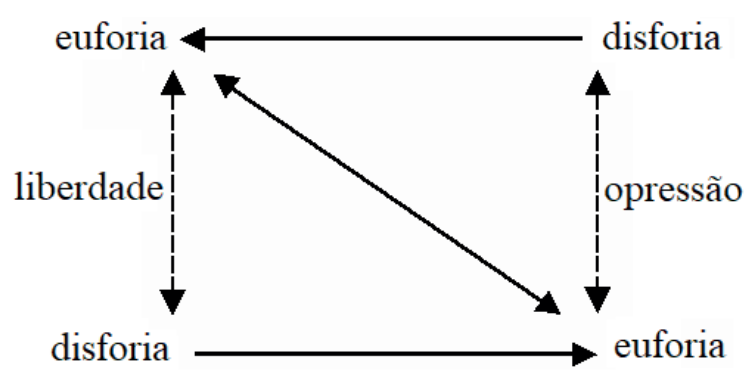

Fonte: Fontanille (2018)

Segundo Fontanille (2018, p. 62), “o quadrado semiótico apresenta-se como a reunião dos dois tipos de oposições binárias em um só sistema" que na análise aqui realizada se configura pela oposição semântica "opressão vs. Liberdade" que dá início ao percurso gerativo de sentido, mostrando a direção da análise semiótica e as tensões que a envolvem.

Portanto, segundo Barros (2011, p. 79), “as estruturas fundamentais convertem-se em estruturas narrativas, a narrativa torna-se discurso", e o discurso se divide entre os planos de exame dos processos significantes: o plano de conteúdo e o plano de expressão, o que para Fontanille (2018, p.56), "a esquematização e a subsequente articulação dos processos significantes são características intrínsecas ao discurso", na medida em que os signos realizam o intercâmbio entre a realidade sensível e simbólica com a geração do sentido, atualizando-se pelo discurso, no momento de sua enunciação. Por fim, sublinhamos que os arranjos de linguagem podem servir a outros fins que os de sua finalidade primeira, como no cartaz analisado. 


\section{Considerações Finais}

Depois dessas ponderações, constatamos que o dispositivo ora analisado, no caso uma mídia impressa que veicula, por meio de um cartaz de vestibular UEG/2016-1, uma propaganda cujo intuito, certamente, não seria desprestigiar o candidato negro, mas que, entretanto, de forma subliminar, propõe uma mudança radical através do imperativo, "transforme-se" linguagem conativa em articulação com a imagem sugerida, que se reveste de uma falsa isenção estereotipada do homem negro. Assim mediante a análise semiótica aqui proposta, podemos afirmar que o cartaz analisado é de longe apenas um convite ao vestibular, ele tornou-se um signo semiótico capaz de levar seus interlocutores à manutenção da representação estereotipada da pessoa negra.Em contrapartida, na contemporaneidade, esse tipo de produção tem sido objeto de resistência e de resiliência.

Observamos ainda que no discurso a imagem do negro é subjugada face ao modelo europeu dominador do homem branco. No contexto de cultura, tal figura incivil dilui-se entre o texto e o discurso legitimando, de novo, uma sub-representação do protagonismo negro face à elitização acadêmica. É como se estivéssemos sob um "determinismo racial", em que o negro tivesse que ser transformado e reinventado para se adequar ao contexto social e cultural dominante, daí concluirmos que os mesmos discursos do homem branco colonizador ainda circulam na atualidade, sob a ordem de discursos racistas e preconceituosos, ainda que camuflados.

Ora, o cartaz analisado, enquanto texto e gênero do 
discurso, estabelece profundas relações com seu contexto de produção e de recepção; e são essas relações que determinam a sua discursivização, por meio de semioses. No nível discursivo, por meio da sintaxe discursiva, o enunciador deixou marcas na enunciação, que evidenciam o posicionamento autoritário, opressor e dissimulado do sujeito enunciador. No plano de expressão do texto, encontramos o uso da imagem de um homem negro, sendo uma inserção marginalizada dessa imagem e muito aquém de promover a equidade entre as raças, ou ainda melhor, entre a única raça: a humana.

Ao enunciar "O conhecimento reinventa tudo... transformese", o leitor, de forma imperativa, é convidado ao novo, ao bom, ao hegemônico, a transformar-se pela aquisição de conhecimento dado pela Universidade Estadual de Goiás. Mas o que seria esse "tudo"? O que é necessário "transformar-se"? Foram exatamente estas duas perguntas junto a imagem centralizada de um homem negro presentes no cartaz da UEG que nos levou a uma inquietação enquanto leitores críticos. E é perturbador pensar que para estas perguntas espera-se o apagamento de uma identidade negra, de uma cultura negra, de um povo negro, sob a imperatividade da reinvenção e da transformação do ser humano.

No nível fundamental da análise do percurso gerativo de sentido, as oposições semânticas mínimas encontradas apontam para um sujeito "opressor" e seu alvo, o sujeito "oprimido". As cores, a imagem e as emoções correspondem ao PE; o léxico, a sintaxe e a semântica correspondem ao PC; todos esses recursos semióticos são portadores de semioses e se cruzam revelando sutilezas do texto analisado dentro do percurso gerativo de sentido. 
No nível narrativo, os sujeitos envolvidos estão presos aos seus interesses, por meio do programa narrativo da manipulação em que um sujeito manipula e exerce domínio sobre o querer do outro. No nível discursivo, os temas e as figuras descrevem um discurso opressor sob a tensão da relação entre o oprimido e seu opressor.

Para encerrar, não nos interessou analisar as políticas de acesso aos cursos de graduação da Universidade Estadual de Goiás e nem seus entraves ideológicos e políticos, muito menos colocar a UEG no centro de nossas análises ou como objeto delas, contudo muito nos interessou o cartaz de divulgação do vestibular de 2016/1 da UEG, que foi insensato, desmedido, estereotipado e solidário ao racismo e ao preconceito racial. É sabido que a UEG tem se dedicado ao combate do racismo estrutural e institucional, com ações afirmativas como, por exemplo, o uso de cotas raciais para afrodescendentes, indígenas e refugiados, e, no geral, tem reformulado suas políticas de acesso aos cursos de graduação da universidade. Fato que não condiz com a mídia veiculada que traz em seus meandros os ranços de Brasil colônia, que certamente ainda estão bem entranhados em nossa cultura.

\section{Referências}

BARROS, Diana Luz P. Teoria semiótica do texto. São Paulo: Ática, 2011.

BENVENISTE, Émile. Problemas de linguística geral. São Paulo: Nacional, Ed. da Universidade de São Paulo, 1976.

BORBA, Francisco da Silva (Coord.). Dicionário gramatical de verbos do português contemporâneo do Brasil. São Paulo: EDUNESP, 1997. 
CASTILHO, A. T. Gramática do português brasileiro. São Paulo: Contexto, 2014

FIORIN, José Luiz. As astúcias da enunciação: as categorias de pessoa, espaço e tempo. 3. ed. São Paulo: Contexto, 2016.

FIORIN, José Luiz. Elementos de análise do discurso. 10. ed. São Paulo: Contexto, 2001.

FIORIN, José Luiz. Introdução à linguística II. 5. ed. São Paulo: Contexto, 2011.

FLOCH, Jean-Marie. Alguns conceitos fundamentais em semiótica geral. In:__. Documentos de estudo do centro de pesquisas sociossemióticas. São Paulo: Centro de Pesquisas Sociossemióticas, 2001. p. 9-29.

FONTANILLE, Jacques. Semiótica do discurso. 2. ed. São Paulo: Contexto, 2018.

GREIMAS, Algirdas Julien. Da imperfeição. 2. ed. São Paulo: Estação das Letras e Cores, 2017.

GREIMAS, Algirdas Julien. Por uma teoria do discurso poético. In: _. Ensaios de semiótica. Tradução de Heloísa de Lima Dantas. São Paulo: Cultrix, 1975.

GREIMAS, Algirdas Julien. Semântica estrutural. 2. ed. São Paulo: Cultrix, 1966.

GREIMAS, Algirdas Julien; COURTÉS, Joseph. Dicionário de semiótica. 2. ed. São Paulo: Contexto, 2011.

GREIMAS, Algirdas Julien; COURTÉS, Joseph. Sémiotique: dictionnarie raisonné da la théoria du language. Paris: Hachette, 1979. 
HJELMSLEV, L. Prolegômenos a uma teoria da linguagem.

Tradução de J. Teixeira Coelho Neto. São Paulo: Perspectiva, 1973.

LANDOWSKI, Eric. Presenças do outro. São Paulo: Perspectiva, 2012.

SANTOS, Boaventura de Sousa. Reconhecer para libertar: os caminhos do cosmopolitanismo multicultural. Rio de Janeiro: Civilização Brasileira, 2003.

SAUSSURE, Ferdinando. Curso de linguística geral. 27. ed. São Paulo: Cultrix, 2006.

TEIXEIRA, Lúcia. Entre dispersão e acúmulo: para uma metodologia de análise de textos sincréticos. In:

Gragoatá. Niterói: UFF, 2004.

UNIVERSIDADE ESTADUAL DE GOIÁS - UEG. Centro de Comunicação Institucional - CeCom. Disponível em: <http:// www.comunicacao.ueg.br/>. Acesso em: 12 out. 2016. 